This is the post print version of the article, which has been published in Bioorganic chemistry. 2018, 78 406-410. http://dx.doi.org/10.1016/j.bioorg.2018.04.010

\title{
Activation studies with amines and amino acids of the $\beta$-carbonic anhydrase from the pathogenic protozoan Leishmania donovani chagasi
}

\section{Andrea Angeli, ${ }^{a}$ William A. Donald, ${ }^{\mathrm{b}}$ Seppo Parkkilac ${ }^{\mathrm{c}}$ and Claudiu T. Supuran ${ }^{\mathrm{a}, \mathrm{b} *}$}

${ }^{a}$ Università degli Studi di Firenze, Dipartimento Neurofarba, Sezione di Scienze Farmaceutiche e Nutraceutiche, Via U. Schiff 6, 50019 Sesto Fiorentino, Florence, Italy.

bSchool of Chemistry, University of New South Wales, Sydney, New South Wales, 2052, Australia.

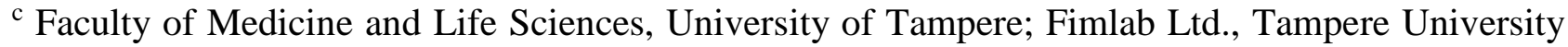
Hospital, 33520 Tampere, Finland.

Abstract. The activation of a $\beta$-class carbonic anhydrase (CAs, EC 4.2.1.1) from Leishmania donovani chagasi (LdcCA) was investigated using a panel of natural and non-natural amino acids and amines. The most effective activators belonged to the amine class, with histamine, dopamine, serotonin, 2-pyridyl-methylamine and 4-(2-aminoethyl)-morpholine with activation constants in the range of $0.23-0.94 \mu \mathrm{M}$. In addition, 2-(2-aminoethyl)pyridine and 1-(aminoethyl)-piperazine were even more effective activators ( $\mathrm{K}_{\mathrm{AS}}$ of 9-12 nM). Amino acids such as L-/D-His, L-/D-Phe, L-/DDOPA, L-/D-Trp and L-/D-Tyr were slightly less effective activators compared to the amines, but showed activation constants in the low micromolar range $(1.27-9.16 \mu \mathrm{M})$. Many of the investigated activators are autacoids that are present in rather high concentrations in different tissues of the host mammals infected by these parasites. As CA activators have not yet been investigated for protozoan CAs, this study may be relevant for an improved understanding of the role of this enzyme in the life cycle of Leishmania.

Keywords: carbonic anhydrase; metalloenzymes, pathogens; activators; Leishmania donovani chagasi

*Corresponding authors: Tel/Fax: +39-055-4573729, E-mail: claudiu.supuran@unifi.it (Claudiu T. Supuran). 


\section{Introduction}

Leishmaniasis is a rather diffuse sub-tropical disease provoked by protozoan belonging to Leishmania spp. ${ }^{1,2}$ There are multiple forms of this disease, among which the visceral (VL), caused by $L$. infantum and L. donovani, as well as the tegumentary forms of the disease, which may include the cutaneous (CL), diffuse (DCL), and muco-cutaneous (MCL) leishmaniases. ${ }^{1,2}$ The disease is transmitted by sand flies, and the life cycle of the pathogen is rather complex, as one of its developmental forms, the amastigote, dwells within immunological cells of the host, making its targeting by the immune system or by drugs rather challenging. ${ }^{1,2}$ There are limited available drugs to treat this condition, and many strains of the parasite are increasingly resistant to drug treatment. Pentavalent antimonium salts (such as sodium stibogluconate, used via the parenteral route), the orally available miltefosine, or parenterally used paromomycin, and amphotericin B, show various degrees of resistance worldwide. ${ }^{1,2}$ Thus, there is a strong need to design alternative therapies and to understand in more detail the life cycle of the parasite and its interactions with the mammalian host. Recently, we have proposed protozoan carbonic anhydrases (CAs, EC 4.2.1.1) as potential targets for dealing with this problem, showing that in L. donovani chagasi, ${ }^{3,4}$ Trypanosoma cruzi, ${ }^{5-7}$ or Plasmodium falciparum, ${ }^{8-11}$ members of this family of enzymes are present, and that their inhibition interferes with the growth of the parasites in vitro and in vivo. ${ }^{2-11}$ L. donovani chagasi encodes for a $\beta$-class CA (denominated LdcCA), ${ }^{3}$ T. cruzi for an $\alpha$-CA (TcCA), ${ }^{5}$ and in P. falciparum, a new genetic family of these enzymes, the $\eta$-CA class has been discovered (PfaCA) ${ }^{8}$ These three protozoans thus encode CAs belonging to three different genetic families, which suggests that their detailed investigation may lead to the discovery of potential drug targets with activities that can be selectively modulated for the management of the diseases they provoke. However, in contrast to the CA inhibitors (CAIs), were shown to inhibit the growth of these protozoan species, investigation of the CA activators (CAAs) have been limited. ${ }^{12,13}$ Such compounds participate to the CA catalytic cycle, which is shown schematically in Equations 1 and 2 (where ' $E$ ' denotes enzyme):

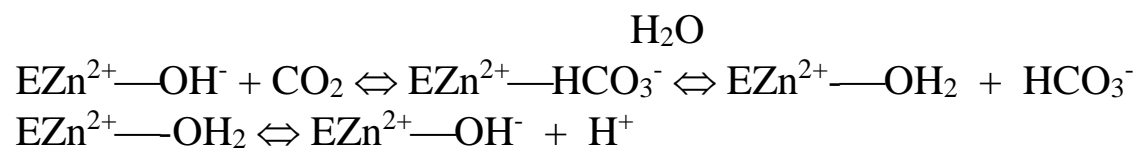

The first step involves a zinc-bound hydroxide species of the enzyme nucleophilically attacking a $\mathrm{CO}_{2}$ substrate that is bound in a hydrophobic pocket nearby in an optimal orientation for the hydration reaction (Equation 1). ${ }^{14,15}$ Bicarbonate formed in the hydration reaction replaced by an incoming water molecule to generate the catalytic acid form of the enzyme, $\mathrm{EZn}^{2+}-\mathrm{OH}_{2}$ (Equation 1). For the regeneration of the zinc hydroxide species, a proton transfer reaction occurs from the 
$\mathrm{Zn}$ (II)-bound water molecule to the external medium (Equation 2), which is the rate-determining step of the entire catalytic cycle.

$$
\begin{gathered}
\mathrm{EZn}^{2+}-\mathrm{OH}_{2}+\mathrm{A} \Leftrightarrow\left[\mathrm{EZn}^{2+}-\mathrm{OH}_{2}-\mathrm{A}\right] \Leftrightarrow\left[\mathrm{EZn}^{2+}-\mathrm{OH}^{-}-\mathrm{AH}^{+}\right] \Leftrightarrow \mathrm{EZn}^{2+}-\mathrm{OH}^{-}+\mathrm{AH}^{+} \\
\text {enzyme - activator complexes }
\end{gathered}
$$

In the presence of activators ( $\mathrm{A}$ in Equation 3), the formation of enzyme-activator complexes occurs, in which the proton transfer reaction becomes intramolecular and thus, more efficient than the corresponding intermolecular process. ${ }^{14,15}$ This mechanism of CA activation was demonstrated by kinetic and crystallographic studies for the human isoforms hCA I and II. ${ }^{16}$ Based on crystal structures, the activator was bound at the entrance to the active site cavity. Most of the activators belong to the amino and/or amino acid chemotypes, and possess moieties with an appropriate $\mathrm{p} K_{\mathrm{a}}$ (generally in the range of 6-8) for efficient proton shuttling processes between the active site and the environment. $^{14-16}$

CAAs belonging to various classes were extensively investigated for the activation of all mammalian (human) CA isoforms known to date, hCA I - XIV. ${ }^{17-21}$ Several drug design studies for CAAs belonging to the amine and amino acid classes have also been reported, and led to the discovery of the activation profile of the different isoforms with several classes of activators. ${ }^{17-21}$ Recently, the potential of this class of pharmacological agents for the therapy of memory disorder and cognition impairment has also been demonstrated. ${ }^{22}$ However, unlike CAIs, which are clinically used as diuretics, ${ }^{23}$ antiglaucoma drugs, ${ }^{24}$ antiobesity, ${ }^{25}$ antitumor, ${ }^{26}$ anti-neuropathic pain, ${ }^{27}$ or anti-arthritis agents, ${ }^{28}$ there are no clinically approved CAAs. Natural and non-natural amino acids and amines of type 1-19 are among the most investigated simple CAAs, and they were evaluated in the present study (Fig. 1). These compounds were investigated for their potential as CAAs against many classes of CAs, including a limited number of bacterial CAs. ${ }^{29}$ However, no protozoan CA enzymes have been investigated for their activation to date. Here we report the first activation study of LdcCA, the $\beta$ class enzyme from the protozoan, L. donovani chagasi, one of the causative agents of visceral leishmaniasis.

\section{Results and Discussion}

To confirm that the activator binds to a different site than the substrate, the effect of the presence of L-Trp on the enzyme kinetics was investigated (Table 1). We have chosen this amino acid derivatives for the detailed kinetic studies due to the fact that it is a rather effective activator of many CAs, and its X-ray crystal structure in adduct with hCA II has also been reported. ${ }^{13}$ Furthermore, this amino acid is present in rather high concentrations in many tissues in vertebrates, including humans, being the precursor of important autacoids/neurotransmitters such as serotonin. ${ }^{13}$ 
The $\mathrm{K}_{\mathrm{m}}$ value does not depend on the presence of L-Trp. In contrast, $\mathrm{k}_{\mathrm{cat}}$ depends strongly on the presence of L-Trp. For example, the use of $10 \mu \mathrm{M}$ L-Trp resulted in the $\mathrm{k}_{\mathrm{cat}}$ of LdcCA increasing by 3.05 times than without the activator (Table 1). These data are as expected, and confirm that the activator is not binding to the same site as the substrate, which has been documented by X-ray crystallography for the human enzymes. ${ }^{13,16 a}$ Moreover, L-Trp is a more effective towards LdcCA than the human enzymes used for comparison purposes.

Table 1: Activation of human carbonic anhydrase (hCA) isozymes I, II, and LdcCA with L-Trp, at $25^{\circ} \mathrm{C}$, for the $\mathrm{CO}_{2}$ hydration reaction. ${ }^{30}$

\begin{tabular}{lllll}
\hline Isozyme & $\begin{array}{l}\mathrm{k}_{\mathrm{cat}}{ }^{*} \\
\left(\mathrm{~s}^{-1}\right)\end{array}$ & $\begin{array}{l}\mathrm{K}_{\mathrm{M}}^{*} \\
(\mathrm{mM})\end{array}$ & $\begin{array}{l}\left(\mathrm{k}_{\mathrm{cat}}\right)_{\mathrm{L}-T r p} * * \\
\left(\mathrm{~s}^{-1}\right)\end{array}$ & $\begin{array}{l}\mathrm{K}_{\mathrm{A}} * * *(\mu \mathrm{M}) \\
\mathrm{L}-\mathrm{Trp}\end{array}$ \\
\hline $\mathrm{hCA} \mathrm{I}^{\mathrm{a}}$ & $2.0 \times 10^{5}$ & 4.0 & $3.4 \times 10^{5}$ & 44.0 \\
hCA II $^{\mathrm{a}}$ & $1.4 \times 10^{6}$ & 9.3 & $4.9 \times 10^{6}$ & 27.0 \\
LdcCA $^{\mathrm{b}}$ & $9.35 \times 10^{5}$ & 15.8 & $28.6 \times 10^{5}$ & 4.02 \\
\hline
\end{tabular}

* Observed catalytic rate without activator. $\mathrm{K}_{\mathrm{M}}$ values in the presence and the absence of activators were the same for the various CAs (data not shown).

** Observed catalytic rate in the presence of $10 \mu \mathrm{M}$ activator.

*** The activation constant $\left(\mathrm{K}_{\mathrm{A}}\right)$ for each enzyme was obtained by fitting the observed catalytic enhancements as a function of the activator concentration. ${ }^{13}$ Mean from at least three determinations by a stopped-flow, $\mathrm{CO}_{2}$ hydrase method. ${ }^{30}$ Standard errors were in the range of 5-10 \% of the reported values (data not shown).

${ }^{\mathrm{a}}$ Human recombinant isozymes, from ref..${ }^{13}$; ${ }^{\mathrm{b}}$ Protozoan recombinant enzyme, this work.

The structure-activity relationship (SAR) for the activation of LdcCA with compounds 1-19, can be delineated considering the data shown in Table 2, where the activation data of the human isoforms hCA I and II are also presented for comparison.

All amino acids and amines investigated act as efficient LdcCA activators, with activation constants that range from the low nanomolar ( $9 \mathrm{nM}$ for 17) to the micromolar (15.9 $\mu \mathrm{M}$ for 11). Amines are generally more effective activators compared to the amino acids, except for L-adrenaline 19 (the only secondary amine investigated here) which has the same potency as most of the amino acids ( $\mathrm{K}_{\mathrm{A}}$ of $\left.4.89 \mu \mathrm{M}\right)$. The most effective LdcA activators were aminopyridine $\mathbf{1 6}$ and piperazine $\mathbf{1 7}$ ( $\mathrm{K}_{\mathrm{AS}}$ of $9-12 \mathrm{nM}$ ), which incorporate a heterocyclic ring and the aminoethyl moiety (both of which can participate in proton transfer reactions between the zinc coordinated water and the external milieu). Amines 12-15 and 18, structurally related to the most effective activators discussed above, 
also show an interesting and efficient activating profile, with $\mathrm{K}_{\mathrm{A}}$ s ranging between 0.23 and $0.94 \mu \mathrm{M}$. Thus, the SAR here is rather well defined, with all these compounds possessing the aminoethyl- or aminomethyl tails appended to an aromatic or heterocyclic moiety. X-ray crystallography for adducts of some of these derivatives with hCA I or II showed that both these fragments of the activator are participating to the stabilization of the enzyme-activator complex, by forming hydrogen bonds and hydrophobic interaction with amino acid residues at the entrance of the active site cavity. ${ }^{13,16}$<smiles>N[C@@H](Cc1c[nH]cn1)C(=O)O</smiles>

1: L-His

2: D-His<smiles>N[C@@H](Cc1ccc(O)cc1)C(=O)O</smiles>

9: L-Tyr

10: D-Tyr<smiles>NCCc1c[nH]c2ccc(O)cc12</smiles>

14<smiles>N[C](Cc1ccccc1)C(=O)O</smiles>

3: L-Phe

4: D-Phe<smiles>Nc1ccc(C[C@H](N)C(=O)O)cc1</smiles>

11: $4-\mathrm{H}_{2} \mathrm{~N}-\mathrm{L}-\mathrm{Phe}$<smiles>N[Mg]c1ccccn1</smiles>

15: $n=1$ 16: $n=2$<smiles>N[C@@H](Cc1ccc(O)c(O)c1)C(=O)O</smiles>

5: L-DOPA

6: D-DOPA<smiles>NCCc1c[nH]cn1</smiles>

12<smiles>[X]CCN(CC)CCN</smiles>

17: $\mathrm{X}=\mathrm{NH}$

18: $X=0$<smiles>N[C@@H](Cc1c[nH]c2ccccc12)C(=O)O</smiles>

7: L-Trp

8: D-Trp<smiles>NCCc1ccc(O)c(O)c1</smiles>

13<smiles>CNC[C@H](O)c1ccc(O)c(O)c1</smiles>

19

Fig. 1: Amino acids 1-11 and amines 12-19 investigated as LdcCA activators.

Table 2: Activation constants of hCA I, hCA II and the protozoan enzyme LdcCA with amino acids and amines $\mathbf{1}$ - 19. Data for hCA I and II are from ref. ${ }^{13}$

\begin{tabular}{lllll}
\hline No. & Compound & & $\begin{array}{l}\mathrm{K}_{\mathrm{A}}(\mu \mathrm{M})^{*} \\
\text { hCA II }^{\mathrm{a}}\end{array}$ & LdcCA $^{\mathrm{b}}$ \\
\hline $\mathbf{1}$ & L-His & 0.03 & 10.9 & 8.21 \\
$\mathbf{2}$ & D-His & 0.09 & 43 & 4.13 \\
$\mathbf{3}$ & L-Phe & 0.07 & 0.013 & 9.16 \\
$\mathbf{4}$ & D-Phe & 86 & 0.035 & 3.95
\end{tabular}




$\begin{array}{lllll}\mathbf{5} & \text { L-DOPA } & 3.1 & 11.4 & 1.64 \\ \mathbf{6} & \text { D-DOPA } & 4.9 & 7.8 & 5.47 \\ \mathbf{7} & \text { L-Trp } & 44 & 27 & 4.02 \\ \mathbf{8} & \text { D-Trp } & 41 & 12 & 6.18 \\ \mathbf{9} & \text { L-Tyr } & 0.02 & 0.011 & 8.05 \\ \mathbf{1 0} & \text { D-Tyr } & 0.04 & 0.013 & 1.27 \\ \mathbf{1 1} & \text { 4-H2N-L-Phe } & 0.24 & 0.15 & 15.9 \\ \mathbf{1 2} & \text { Histamine } & 2.1 & 125 & 0.74 \\ \mathbf{1 3} & \text { Dopamine } & 13.5 & 9.2 & 0.81 \\ \mathbf{1 4} & \text { Serotonin } & 45 & 50 & 0.62 \\ \mathbf{1 5} & \text { 2-Pyridyl-methylamine } & 26 & 34 & 0.23 \\ \mathbf{1 6} & \text { 2-(2-Aminoethyl)pyridine } & 13 & 15 & 0.012 \\ \mathbf{1 7} & \text { 1-(2-Aminoethyl)-piperazine } 7.4 & 2.3 & 0.009 \\ \mathbf{1 8} & \text { 4-(2-Aminoethyl)-morpholine } 0.14 & 0.19 & 0.94 \\ \mathbf{1 9} & \text { L-Adrenaline } & 0.09 & 96 & 4.89\end{array}$

* Mean from three determinations by a stopped-flow, $\mathrm{CO}_{2}$ hydrase method. ${ }^{30}$ Standard errors were in the range of 5-10 \% of the reported values (data not shown).

${ }^{\text {a }}$ Human recombinant isozymes, stopped flow $\mathrm{CO}_{2}$ hydrase assay method; ${ }^{13,30}$ ${ }^{\mathrm{b}}$ This work.

The amino acids 1-10 were slightly less effective as LdcCA activators compared to the amines discussed above, with $\mathrm{K}_{\mathrm{A}}$ s ranging between 1.27 and $15.9 \mu \mathrm{M}$. In several cases (D-His, D-Phe, DTyr), the D-enantiomer was more efficient as LdcCA activator compared to the corresponding Lenantiomer, whereas for the DOPA and Trp, the L-enantiomers were the more effective activators compared to the corresponding D-amino acids (Table 1). Small changes in the scaffold of the activator lead to important differences of activity: replacement of the phenolic OH from L-Tyr (9) by an amine moiety (as in 11) lead to an almost 2-fold loss of activating properties.

The activation of the protozoan enzyme was rather different from that of the $\alpha$-class enzymes hCA I and II. For example, L-/D-Tyr were highly effective, nanomolar hCA I and II activators, whereas their effects on LdcCA are seen only at micromolar concentrations. On the contrary, amine 16 may be considered as a LdcCA - selective activator, with a $\mathrm{K}_{\mathrm{A}}$ of $12 \mathrm{nM}$ for the protozoan enzyme and of $13-15 \mu \mathrm{M}$ for the human CAs. Thus, this compound may be used as a pharmacologic tool to explore the role that LdcCA might play in the life cycle of this protozoan and whether CA activation 
is important for the infection or host colonization by Leishmania, in diverse phases of the pathogen's life cycle.

\section{Conclusions}

The first activation study of a protozoan CA is reported here. The $\beta$-class enzyme from Leishmania donovani chagasi (LdcCA) was investigated for its interaction with a panel of natural and non-natural amino acids and amines acting as CAAs of mammalian and bacterial enzymes. Nanomolar activators were identified that belong to the amine class, with histamine, dopamine, serotonin, 2-pyridylmethylamine and 4-(2-aminoethyl)-morpholine (activation constants of 0.23 to $0.94 \mu \mathrm{M})$. The most effective activators were 2-(2-aminoethyl)pyridine and 1-(aminoethyl)-piperazine which had $\mathrm{K}_{\mathrm{A}} \mathrm{s}$ of 9-12 nM. Amino acids such as L-/D-His, L-/D-Phe, L-/D-DOPA, L-/D-Trp and L-/D-Tyr were less effective activators compared to the amines, but showed activation constants in the low micromolar range $(1.27-9.16 \mu \mathrm{M})$. Because activators have not been identified for protozoan CAs, this study should be important for understanding the role that this enzyme has in the life cycle of Leishmania, particularly considering the fact that many of the activators identified are autacoids present in rather high concentrations in different tissues of the host mammals that are infected by these parasites.

\section{Experimental}

4.1. Chemistry. Amino acids and amines 1-19 were commercially available, highest purity reagents from Sigma-Aldrich, Milan, Italy. LdcCA was a recombinant protein produced as reported earlier by our group. ${ }^{3}$

\subsection{CA enzyme activation assay}

An Sx.18Mv-R Applied Photophysics (Oxford, UK) stopped-flow instrument has been used to assay the catalytic activity of various CA isozymes for $\mathrm{CO}_{2}$ hydration reaction. ${ }^{30}$ Phenol red (at a concentration of $0.2 \mathrm{mM}$ ) was used as indicator, working at the absorbance maximum of $557 \mathrm{~nm}$, with $10 \mathrm{mM}$ Hepes ( $\mathrm{pH}$ 7.5) or TRIS ( $\mathrm{pH}$ 8.3) as buffers, $0.1 \mathrm{M} \mathrm{Na}_{2} \mathrm{SO}_{4}$ (for maintaining constant ionic strength), following the CA-catalyzed $\mathrm{CO}_{2}$ hydration reaction for a period of $10 \mathrm{~s}$ at $25{ }^{\circ} \mathrm{C}$. Activity of the $\alpha$-CAs was measured at $\mathrm{pH} 7.5$ whereas that of the $\beta$-class enzymes at $\mathrm{pH} 8.3$ in order to avoid the possibility that their active site is closed. ${ }^{3,12}$ The $\mathrm{CO}_{2}$ concentrations ranged from 1.7 to $17 \mathrm{mM}$ for the determination of the kinetic parameters and activation constants. For each activator at least six traces of the initial 5-10\% of the reaction have been used for determining the initial velocity. The uncatalyzed rates were determined in the same manner and subtracted from the total observed 
rates. Stock solutions of activators $(10 \mathrm{mM})$ were prepared in distilled-deionized water and dilutions up to $1 \mathrm{nM}$ were done thereafter with the assay buffer. Activator and enzyme solutions were preincubated together for 15 min (standard assay at room temperature) prior to assay, in order to allow for the formation of the E-A complex. The activation constant $\left(\mathrm{K}_{\mathrm{A}}\right)$, defined similarly with the inhibition constant $\mathrm{K}_{\mathrm{I}}$, can be obtained by considering the classical Michaelis-Menten equation (equation 4), which has been fitted by non-linear least squares by using PRISM 3:

$$
\mathrm{v}=\mathrm{v}_{\max } /\left\{1+\mathrm{K}_{\mathrm{M}} /[\mathrm{S}]\left(1+[\mathrm{A}]_{\mathrm{f}} / \mathrm{K}_{\mathrm{A}}\right)\right\}
$$

where $[\mathrm{A}]_{\mathrm{f}}$ is the free concentration of activator.

Working at substrate concentrations considerably lower than $\mathrm{K}_{\mathrm{M}}\left([\mathrm{S}]<<\mathrm{K}_{\mathrm{M}}\right)$, and considering that $[A]_{\mathrm{f}}$ can be represented in the form of the total concentration of the enzyme ([E $\left.]_{\mathrm{t}}\right)$ and activator $\left([\mathrm{A}]_{\mathrm{t}}\right)$, the obtained competitive steady-state equation for determining the activation constant is given by equation 5:

$$
\mathrm{v}=\mathrm{v}_{0} \cdot \mathrm{K}_{\mathrm{A}} /\left\{\mathrm{K}_{\mathrm{A}}+\left([\mathrm{A}]_{\mathrm{t}}-0.5\left\{\left([\mathrm{~A}]_{\mathrm{t}}+[\mathrm{E}]_{\mathrm{t}}+\mathrm{K}_{\mathrm{A}}\right)-\left([\mathrm{A}]_{\mathrm{t}}+[\mathrm{E}]_{\mathrm{t}}+\mathrm{K}_{\mathrm{A}}\right)^{2}-4[\mathrm{~A}]_{\mathrm{t}} \cdot[\mathrm{E}]_{\mathrm{t}}\right)^{1 / 2}\right\}\right\}
$$

where $\mathrm{v}_{0}$ represents the initial velocity of the enzyme-catalyzed reaction in the absence of activator. $^{12,13,16}$

Acknowledgments. This research was financed in part by an Australian Research Council project (DP160102681). Production of recombinant LdcCA was supported by funding from the Academy of Finland and Sigrid Juselius Foundation. 


\section{References}

1. Ponte-Sucre A, Gamarro F, Dujardin JC, Barrett MP, López-Vélez R, García-Hernández R, Pountain AW, Mwenechanya R, Papadopoulou B. Drug resistance and treatment failure in leishmaniasis: A 21st century challenge. PLoS Negl Trop Dis. 2017; 11: e0006052.

2. a) Vermelho AB, Capaci GR, Rodrigues IA, Cardoso VS, Mazotto AM, Supuran CT. Carbonic anhydrases from Trypanosoma and Leishmania as anti-protozoan drug targets. Bioorg Med Chem. 2017; 25: 1543-1555; b) Supuran CT. Inhibition of carbonic anhydrase from Trypanosoma cruzi for the management of Chagas disease: an underexplored therapeutic opportunity. Future Med Chem. 2016; 8: 311-324.

3. Syrjänen L, Vermelho AB, Rodrigues Ide A, Corte-Real S, Salonen T, Pan P, Vullo D, Parkkila S, Capasso C, Supuran CT. Cloning, characterization, and inhibition studies of a $\beta$-carbonic anhydrase from Leishmania donovani chagasi, the protozoan parasite responsible for leishmaniasis. J Med Chem. 2013; 56: 7372-7381.

4. Capasso C, Supuran CT. Bacterial, fungal and protozoan carbonic anhydrases as drug targets. Expert Opin Ther Targets. 2015; 19: 1689-1704.

5. Pan P, Vermelho AB, Capaci Rodrigues G, Scozzafava A, Tolvanen ME, Parkkila S, Capasso C, Supuran CT. Cloning, characterization, and sulfonamide and thiol inhibition studies of an $\alpha$-carbonic anhydrase from Trypanosoma cruzi, the causative agent of Chagas disease. J Med Chem. 2013; 56: 1761-1771.

6. a) Vermelho AB, da Silva Cardoso V, Ricci Junior E, Dos Santos EP, Supuran CT. Nanoemulsions of sulfonamide carbonic anhydrase inhibitors strongly inhibit the growth of Trypanosoma cruzi. J Enzyme Inhib Med Chem. 2018; 33: 139-146; b) de Menezes Dda R, Calvet CM, Rodrigues GC, de Souza Pereira MC, Almeida IR, de Aguiar AP, Supuran CT, Vermelho AB. Hydroxamic acid derivatives: a promising scaffold for rational compound optimization in Chagas disease. J Enzyme Inhib Med Chem. 2016; 31: 964-973.

7. Nocentini A, Cadoni R, Dumy P, Supuran CT, Winum JY. Carbonic anhydrases from Trypanosoma cruzi and Leishmania donovani chagasi are inhibited by benzoxaboroles. J Enzyme Inhib Med Chem. 2018; 33: 286-289.

8. Del Prete S, Vullo D, Fisher GM, Andrews KT, Poulsen SA, Capasso C, Supuran CT. Discovery of a new family of carbonic anhydrases in the malaria pathogen Plasmodium falciparum--the $\eta$ carbonic anhydrases. Bioorg Med Chem Lett. 2014; 24: 4389-4396

9. a) Supuran CT, Capasso C. The $\eta$-class carbonic anhydrases as drug targets for antimalarial agents. Expert Opin Ther Targets. 2015; 19: 551-563; b) Vullo D, Del Prete S, Fisher GM, Andrews KT, 
Poulsen SA, Capasso C, Supuran CT. Sulfonamide inhibition studies of the $\eta$-class carbonic anhydrase from the malaria pathogen Plasmodium falciparum. Bioorg Med Chem. 2015; 23: 526531.

10. De Simone G, Di Fiore A, Capasso C, Supuran CT. The zinc coordination pattern in the $\eta$ carbonic anhydrase from Plasmodium falciparum is different from all other carbonic anhydrase genetic families. Bioorg Med Chem Lett. 2015; 25: 1385-1389.

11. Del Prete S, De Luca V, De Simone G, Supuran CT, Capasso C. Cloning, expression and purification of the complete domain of the $\eta$-carbonic anhydrase from Plasmodium falciparum. $\mathrm{J}$ Enzyme Inhib Med Chem. 2016; 31(sup4): 54-59.

12. a) Tu C, Rowlett RS, Tripp BC, et al. Chemical rescue of proton transfer in catalysis by carbonic anhydrases in the beta- and gamma-class. Biochemistry. 2002; 41: 15429-35; b) Smith KS, IngramSmith C, Ferry JG. Roles of the conserved aspartate and arginine in the catalytic mechanism of an archaeal beta-class carbonic anhydrase. J Bacteriol. 2002; 184: 4240-5.

13. a) Temperini C, Scozzafava A, Supuran CT. Carbonic anhydrase activation and the drug design. Curr Pharm Des. 2008; 14: 708-715; b) Temperini C, Scozzafava A, Vullo D, Supuran CT. Carbonic anhydrase activators. Activation of isozymes I, II, IV, VA, VII, and XIV with l- and d-histidine and crystallographic analysis of their adducts with isoform II: engineering proton-transfer processes within the active site of an enzyme. Chemistry. 2006; 12: 7057-7066; c) Temperini C, Scozzafava A, Vullo D, Supuran CT. Carbonic anhydrase activators. Activation of isoforms I, II, IV, VA, VII, and XIV with L- and D-phenylalanine and crystallographic analysis of their adducts with isozyme II: stereospecific recognition within the active site of an enzyme and its consequences for the drug design. J Med Chem. 2006; 49: 3019-3027; d) Temperini C, Innocenti A, Scozzafava A, Supuran CT. Carbonic anhydrase activators: kinetic and X-ray crystallographic study for the interaction of D- and L-tryptophan with the mammalian isoforms I-XIV. Bioorg Med Chem. 2008; 16: 8373-8378.

14. a) Supuran CT. Carbonic anhydrases: from biomedical applications of the inhibitors and activators to biotechnological use for $\mathrm{CO}_{2}$ capture. J Enzyme Inhib Med Chem 2013; 28:229-30; b) Supuran CT. How many carbonic anhydrase inhibition mechanisms exist? J Enzyme Inhib Med Chem 2016; 31:345-60; c) Alterio V, Di Fiore A, D'Ambrosio K, Supuran CT, De Simone, G. Multiple binding modes of inhibitors to carbonic anhydrases: how to design specific drugs targeting 15 different isoforms? Chem Rev 2012; 112:4421-4468; d) Abbate F, Winum JY, Potter BV, Casini A, Montero JL, Scozzafava A, Supuran CT. Carbonic anhydrase inhibitors: X-ray crystallographic structure of the adduct of human isozyme II with EMATE, a dual inhibitor of carbonic anhydrases and steroid sulfatase. Bioorg Med Chem Lett. 2004; 14: 231-234; e) Capasso C, Supuran CT. An 
overview of the alpha-, beta-and gamma-carbonic anhydrases from Bacteria: can bacterial carbonic anhydrases shed new light on evolution of bacteria? J Enzyme Inhib Med Chem. 2015; 30: 325-332 15. a) Supuran CT. Advances in structure-based drug discovery of carbonic anhydrase inhibitors. Expert Opin Drug Discov. 2017; 12: 61-88; b) Supuran CT. Structure and function of carbonic anhydrases. Biochem J. 2016; 473: 2023-32; c) Supuran CT. Carbonic anhydrases: novel therapeutic applications for inhibitors and activators. Nat Rev Drug Discov 2008; 7:168-81; d) Neri D, Supuran CT. Interfering with $\mathrm{pH}$ regulation in tumours as a therapeutic strategy. Nat. Rev. Drug Discov. 2011, 10, 767-777; e) Supuran CT, Vullo D, Manole G, Casini A, Scozzafava A. Designing of novel carbonic anhydrase inhibitors and activators. Curr Med Chem Cardiovasc Hematol Agents. 2004; 2: 49-68.

16. a) Briganti F, Mangani S, Orioli P, Scozzafava A, Vernaglione G, Supuran CT. Carbonic anhydrase activators: X-ray crystallographic and spectroscopic investigations for the interaction of isozymes I and II with histamine. Biochemistry 1997;36:10384-92; b) Clare B.W., Supuran C.T., Carbonic anhydrase activators. 3: structure-activity correlations for a series of isozyme II activators. J Pharm Sci 1994;83:768-773; c) Ilies M, Scozzafava A, Supuran CT. Carbonic anhydrase activators, in: Supuran CT, Scozzafava A, Conway J (Eds.) Carbonic Anhydrase - Its inhibitors and activators, CRC Press, Boca Raton, 2004, pp. 317-52; d) Akocak S, Lolak N, Vullo D, Durgun M, Supuran CT. Synthesis and biological evaluation of histamine Schiff bases as carbonic anhydrase I, II, IV, VII, and IX activators. J Enzyme Inhib Med Chem. 2017; 32: 1305-1312; e) Licsandru E, Tanc M, Kocsis I, Barboiu M, Supuran CT. A class of carbonic anhydrase I - selective activators. J Enzyme Inhib Med Chem. 2017; 32: 37-46.

17. a) Temperini C, Innocenti A, Scozzafava A, Mastrolorenzo A, Supuran CT. Carbonic anhydrase activators: L-Adrenaline plugs the active site entrance of isozyme II, activating better isoforms I, IV, VA, VII, and XIV. Bioorg Med Chem Lett. 2007; 17: 628-635; b) Temperini C, Scozzafava A, Puccetti L, Supuran CT. Carbonic anhydrase activators: X-ray crystal structure of the adduct of human isozyme II with L-histidine as a platform for the design of stronger activators. Bioorg Med Chem Lett. 2005; 15: 5136-5141; c) Temperini C, Scozzafava A, Supuran CT. Carbonic anhydrase activators: the first X-ray crystallographic study of an adduct of isoform I. Bioorg Med Chem Lett. 2006; 16: 5152-5156.

18. a) Vullo D, Nishimori I, Innocenti A, Scozzafava A, Supuran CT. Carbonic anhydrase activators: an activation study of the human mitochondrial isoforms VA and VB with amino acids and amines. Bioorg Med Chem Lett. 2007; 17: 1336-1340; b) Pastorekova S, Vullo D, Nishimori I, Scozzafava A, Pastorek J, Supuran CT. Carbonic anhydrase activators: activation of the human tumor-associated isozymes IX and XII with amino acids and amines. Bioorg Med Chem. 2008; 16: 3530-3536; c) 
Nishimori I, Onishi S, Vullo D, Innocenti A, Scozzafava A, Supuran CT. Carbonic anhydrase activators. The first activation study of the human secretory isoform VI. Bioorg Med Chem 2007: 15: 5351 - 5357.

19. a) Parkkila S, Vullo D, Puccetti L, Parkkila AK, Scozzafava A, Supuran CT. Carbonic anhydrase activators: activation of isozyme XIII with amino acids and amines. Bioorg Med Chem Lett. 2006; 16: 3955-3959; b) Vullo D, Innocenti A, Nishimori I, Scozzafava A, Kaila K, Supuran CT. Carbonic anhydrase activators: activation of the human isoforms VII (cytosolic) and XIV (transmembrane) with amino acids and amines. Bioorg Med Chem Lett. 2007; 17: 4107-4112; c) Vullo D, Nishimori I, Scozzafava A, Supuran CT. Carbonic anhydrase activators: Activation of the human cytosolic isozyme III and membrane-associated isoform IV with amino acids and amines. Bioorg Med Chem Lett. 2008; 18: 4303-4307.

20. a) Innocenti A, Hilvo M, Parkkila S, Scozzafava A, Supuran CT. Carbonic anhydrase activators. Activation of the membrane-associated isoform XV with amino acids and amines. Bioorg Med Chem Lett. 2009; 19: 3430-3433; b) Supuran CT, Dinculescu A, Balaban AT. Carbonic anhydrase activators. Part 5. CA II activation by 2,4,6-trisubstituted pyridinium cations with 1-( $\omega$-aminoalkyl) side chains. Rev Roum Chim. 1993; 38: 343-349; c) Supuran CT, Barboiu M, Luca C, Pop E, Brewster ME, Dinculescu A. Carbonic anhydrase activators. Part 14. Synthesis of mono- and bispyridinium salt derivatives of 2-amino-5-(2-aminoethyl)- and 2-amino-5-(3-aminopropyl)-1,3,4thiadiazole, and their interaction with isozyme II. Eur J Med Chem. 1996; 31: 597-606; d) Ilies MA, Banciu MD, Ilies M, Chiraleu F, Briganti F, Scozzafava A, Supuran CT. Carbonic anhydrase activators. Part 17. Synthesis and activation study of a series of 1-(1,2,4-triazole-(1H)-3-yl)-2,4,6trisubstituted-pyridinium salts against isozymes I, II and IV. Eur J Med Chem. 1997; 32: 911-918.

21. a) Ilies M, Banciu MD, Ilies MA, Scozzafava A, Caproiu MT, Supuran CT. Carbonic anhydrase activators: design of high affinity isozymes I, II, and IV activators, incorporating tri-/tetrasubstitutedpyridinium-azole moieties. J Med Chem. 2002; 45: 504-510; b) Dave K, Scozzafava A, Vullo D, Supuran CT, Ilies MA. Pyridinium derivatives of histamine are potent activators of cytosolic carbonic anhydrase isoforms I, II and VII. Org Biomol Chem. 2011; 9: 2790-2800; c) Dave K, Ilies MA, Scozzafava A, Temperini C, Vullo D, Supuran CT. An inhibitor-like binding mode of a carbonic anhydrase activator within the active site of isoform II. Bioorg Med Chem Lett. 2011; 21: 2764-2768. 22. a) Canto de Souza L, Provensi G, Vullo D, Carta F, Scozzafava A, Costa A, Schmidt SD, Passani MB, Supuran CT, Blandina P. Carbonic anhydrase activation enhances object recognition memory in mice through phosphorylation of the extracellular signal-regulated kinase in the cortex and the hippocampus. Neuropharmacology. 2017; 118: 148-156; b) Supuran CT. Carbonic anhydrase activators. Future Med Chem. 2018; 10: 561-573. 
23. Carta F, Supuran CT. Diuretics with carbonic anhydrase inhibitory action: a patent and literature review (2005 - 2013). Expert Opin. Ther. Pat. 2013, 23, 681-691.

24. Masini E, Carta F, Scozzafava A, Supuran CT. Antiglaucoma carbonic anhydrase inhibitors: a patent review. Expert Opin. Ther. Pat. 2013, 23, 705-716.

25. a) Scozzafava A, Supuran CT, Carta F. Antiobesity carbonic anhydrase inhibitors: a literature and patent review. Expert Opin. Ther. Pat. 2013, 23, 725-735; b) Supuran CT. Carbonic Anhydrases and Metabolism. Metabolites. 2018; 8: E25.

26. a) Monti SM, Supuran CT, De Simone G. Anticancer carbonic anhydrase inhibitors: a patent review (2008 - 2013). Expert Opin. Ther. Pat. 2013, 23, 737-749; b) Supuran CT. Carbonic Anhydrase Inhibition and the Management of Hypoxic Tumors. Metabolites. 2017, 7, E48; c) Ward C, Langdon SP, Mullen P, Harris AL, Harrison DJ, Supuran CT, Kunkler IH. New strategies for targeting the hypoxic tumour microenvironment in breast cancer. Cancer Treat Rev. 2013; 39: 171179; d) Garaj V, Puccetti L, Fasolis G, et al. Carbonic anhydrase inhibitors: novel sulfonamides incorporating 1,3,5-triazine moieties as inhibitors of the cytosolic and tumour-associated carbonic anhydrase isozymes I, II and IX. Bioorg Med Chem Lett. 2005; 15: 3102-3108; e) Casey JR, Morgan PE, Vullo D, Scozzafava A, Mastrolorenzo A, Supuran CT. Carbonic anhydrase inhibitors. Design of selective, membrane-impermeant inhibitors targeting the human tumor-associated isozyme IX. J Med Chem. 2004; 47: 2337-2347.

27. a) Supuran CT. Carbonic anhydrase inhibition and the management of neuropathic pain. Expert Rev Neurother. 2016; 16: 961-968; b) Di Cesare Mannelli L, Micheli L, Carta F, Cozzi A, Ghelardini C, Supuran CT. Carbonic anhydrase inhibition for the management of cerebral ischemia: in vivo evaluation of sulfonamide and coumarin inhibitors. J Enzyme Inhib Med Chem. 2016; 31: 894-899. 28. a) Margheri F, Ceruso M, Carta F, Laurenzana A, Maggi L, Lazzeri S, Simonini G, Annunziato F, Del Rosso M, Supuran CT, Cimaz R. Overexpression of the transmembrane carbonic anhydrase isoforms IX and XII in the inflamed synovium. J Enzyme Inhib Med Chem. 2016; 31(sup4): 60-63; b) Bua S, Di Cesare Mannelli L, Vullo D, Ghelardini C, Bartolucci G, Scozzafava A, Supuran CT, Carta F. Design and Synthesis of Novel Nonsteroidal Anti-Inflammatory Drugs and Carbonic Anhydrase Inhibitors Hybrids (NSAIDs-CAIs) for the Treatment of Rheumatoid Arthritis. J Med Chem. 2017; 60: 1159-1170.

29. a) Vullo D, De Luca V, Scozzafava A, Carginale V, Rossi M, Supuran CT, Capasso C. The first activation study of a bacterial carbonic anhydrase (CA). The thermostable $\alpha$-CA from Sulfurihydrogenibium yellowstonense YO3AOP1 is highly activated by amino acids and amines. Bioorg Med Chem Lett. 2012; 22: 6324-6327; b) Innocenti A, Zimmerman SA, Scozzafava A, Ferry JG, Supuran CT. Carbonic anhydrase activators: activation of the archaeal beta-class (Cab) and 
gamma-class (Cam) carbonic anhydrases with amino acids and amines. Bioorg Med Chem Lett. 2008; 18: 6194-6198; c) Vullo D, Del Prete S, Osman SM, Alasmary FAS, AlOthman Z, Donald WA, Capasso C, Supuran CT. Comparison of the amine/amino acid activation profiles of the $\beta$ - and $\gamma$ carbonic anhydrases from the pathogenic bacterium Burkholderia pseudomallei. J Enzyme Inhib Med Chem. 2018; 33: 25-30; d) Vullo D, Del Prete S, Osman SM, AlOthman Z, Capasso C, Donald WA, Supuran CT. Burkholderia pseudomallei $\gamma$-carbonic anhydrase is strongly activated by amino acids and amines. Bioorg Med Chem Lett. 2017; 27: 77-80; d) Angeli A, Alasmary FAS, Del Prete S, Osman SM, AlOthman Z, Donald WA, Capasso C, Supuran CT. The first activation study of a $\delta$ carbonic anhydrase: TweCA $\delta$ from the diatom Thalassiosira weissflogii is effectively activated by amines and amino acids. J Enzyme Inhib Med Chem. 2018; 33: 680-685.

30. Khalifah R.G., The carbon dioxide hydration activity of carbonic anhydrase. I. Stop-flow kinetic studies on the native human isoenzymes B and C. J Biol Chem 1971; 246:2561-73 